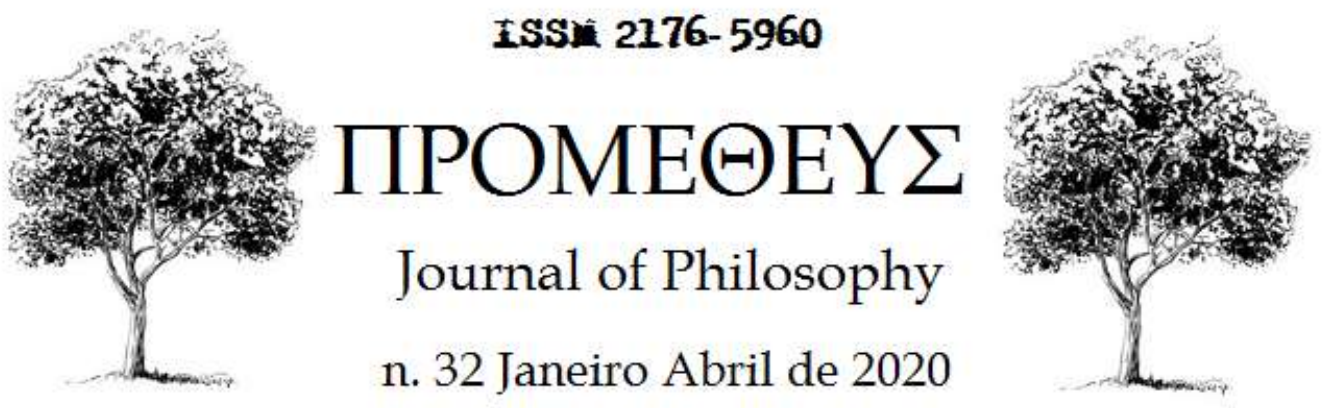

\title{
AS ORIGENS DO USO DO TERMO PROHAIRESIS EM EPICTETO
}

\section{Rafael Rodrigues Pereira Doutor em Filosofia Professor adjunto do departamento de filosofia da UFG}

RESUMO: o presente trabalho pretende explorar diversas hipóteses sobre o uso do termo prohairesis por Epicteto, visando explicar porque um filósofo estoico escolheu um termo de origem aristotélica para expressar o principal conceito de sua filosofia.

PALAVRAS-CHAVE: Epicteto. Prohairesis. Estoicismo.

ABSTRACT: this paper explores some thesis about the use of the word prohairesis by Epictetus. We try to explain why a stoic philosopher uses an Aristotelian notion in order to express the most important concept of his philosophy.

KEYWORDS: Epictetus. Prohairesis. Stoicism. 


\section{Introdução.}

O objetivo deste artigo consiste em realizar uma rápida exposição do debate acerca da origem do uso do termo prohairesis em Epicteto.

Por que deveria haver algum debate sobre isso? Por dois motivos: primeiro, porque se trata de um termo marcado pela tradição peripatética, rival filosófica do estoicismo no tempo de Epicteto. Segundo, porque a própria tradição estoica raramente fez uso desta palavra. Podemos nos perguntar, assim, o que teria levado Epicteto a optar por uma expressão de origem aristotélica para expressar o conceito mais importante de sua própria filosofia. Antes de discutir as possíveis origens do termo, no entanto, cumpre-nos falar rapidamente da importância da noção de prohairesis dentro da filosofia de Epicteto.

Epicteto caracteriza a prohairesis como a faculdade da razão, do uso correto das impressões, dos impulsos negativos e positivos, do desejo e aversão (Disc. I-1.12-13; LONG, 2002, p. 207). O termo que tradicionalmente cumpre esta função na doutrina estoica é hêgemonikon, o que significa, literalmente, a "faculdade governante". Como diz A. A. Long, há várias afinidades entre esta noção e a prohairesis de Epicteto: além de ser a sede da racionalidade, a hêgemonikon é, para os estoicos, o centro da pessoa, nossa disposição moral e epistêmica (LONG, 2002, p. 211). O próprio Epicteto usa o termo com frequência (Disc. III-5.3; III-6.4; III-9.11). O que o teria então levado a considerar necessário elaborar um conceito suplementar, o de prohairesis? Segundo Long, o ponto seria o de que o hêgemonikon inclui a racionalidade, mas não se identifica com ela. Trata-se de uma noção mais ampla, também aplicável à alma dos animais, na medida em que também inclui a capacidade de receber impressões e pensamentos que "ocorrem" em nós (LONG, 2002, p. 211). Epicteto, assim, teria cunhado um termo específico para designar a racionalidade humana (e de Deus), aquelas capacidades e disposições que dependem inteiramente de nós, livres de constrangimentos externos.

Segundo esta interpretação, portanto, Epicteto elaborou o conceito de prohairesis em função da importância, em sua filosofia, de delimitar, de forma mais precisa do que fez a tradição estoica, aquilo que realmente "depende de nós" (tá èf'emin). Suzanne Bobzien, em seu estudo sobre determinismo e liberdade nos estoicos, aponta que a distinção entre aquilo que depende e o que não depende de nós já era 
relevante desde a antiga Stoa, porém há importantes modificações e inovações introduzidas por Epicteto. Em Crisipo, de fato, esta expressão é usada em discussões sobre a responsabilidade moral. Como veremos melhor mais adiante, Crisipo se serve da famosa metáfora do cilindro para argumentar que mesmo em um mundo determinista faz sentido dizer que somos responsáveis por nossas ações, na medida em que somos sua causa principal - ou seja, na medida em que estas ações "dependem de nós", o que está diretamente ligado à nossa capacidade de dar assentimento às impressões. Neste sentido a posição de Crisipo parece se aproximar da de Epicteto, porém há uma importante diferença: este último, de fato, categoriza como o que "depende de nós" somente aquilo que não pode, em nenhuma circunstância, ser imposto externamente. Como diz Bobzien, fazer uma simples caminhada, quando não há impedimentos externos, é algo que depende de nós para Crisipo - sou a causa principal desta caminhada na medida em que dei assentimento a uma impressão impulsiva, "devo caminhar". Para Epicteto, no entanto, o fato de que eu poderia, em princípio, ter sido impedido de caminhar, ainda que isto não tenha ocorrido desta vez, é suficiente para que esta ação não dependa realmente de mim em um sentido forte (BOBZIEN, 1998, p. 332; Cf. Disc. IV-1.68-73). Epicteto considera, assim, como tá èf'emin apenas aquilo que não pode, em nenhuma circunstância, ser objeto de constrangimento externo, aquilo que sempre depende apenas de mim. O que poderia atender a um critério tão exigente? Conforme já comentamos, para Epicteto trata-se da faculdade da razão, do uso correto das impressões, dos impulsos negativos e positivos, do desejo e aversão - em suma, aquilo que o filósofo chamará de prohairesis. Como diz Long, assentimento e impulso são as duas funções mentais básicas da prohairesis, e correspondem exatamente àquilo que Epicteto caracteriza como como tá èf'emin (LONG, 2002, p. 219).

Podemos assim considerar que o conceito de prohairesis é cunhado por Epicteto para caracterizar, de forma mais precisa do que teria sido feito na tradição estoica, aquilo que sempre depende apenas de nós. No entanto, para compreendermos devidamente a centralidade desta noção em sua filosofia, é preciso, ainda, considerar sua relação com a liberdade (èleutería).

Uma das principais teses de Epicteto, de fato, é a de que a prohairesis é "naturalmente livre" (Disc. I-17.21-25). Isso decorre diretamente do fato de seu exercício depender inteiramente de nós: a prohairesis nunca sofre constrangimento externo em um sentido causal estrito. 
Podemos, no entanto, distinguir dois sentidos de liberdade: de fato, a faculdade da prohairesis, ainda que imune à coação externa, pode se perverter e ser mal exercida o que poderíamos, talvez, chamar de "constrangimento interno". Deste mau uso é que resulta o assentimento equivocado às impressões, algo que todos nós fazemos diariamente (Disc. III-19). É preciso, assim, um contínuo exercício de aprimoramento para que a prohairesis seja exercida adequadamente, de acordo com sua condição natural, que é a autonomia plena - o que consiste, como diz Long, em só desejar o que se pode ter, e só rejeitar o que se pode ter aversão (LONG, 2002, p. 217). Outra forma de descrever este estado, seguindo a tradição estoica, seria a de que quando assentimos corretamente às impressões reconhecemos que somente a virtude (que consiste, justamente, no uso correto da prohairesis) é um bem (agathon), e somente o vício (a perversão da prohairesis) é um mal (kakon), todo o resto sendo indiferente (adiaphora) (Disc. II-9.15-16; II-19.13).

Esse é o estado do sábio. Podemos assim considerar que embora em certo sentido todos nasçamos livres, na medida em que a prohairesis não pode nunca ser coagida externamente, existe um sentido mais estrito de liberdade - a liberdade plena, "de fato" - que só pode ser atribuída ao sábio. ${ }^{1}$ Como diz Long, "de acordo com o estoicismo ortodoxo os seres humanos são dotados de impulsos instintivos para virtude ou 'sementes' de virtude, mas a atualização completa dessa potencialidade requer o conhecimento e a consistência do sábio ideal” (LONG, 2002, p. 225, tradução nossa).

Estas considerações nos permitem compreender melhor porque a prohairesis não deve ser entendida como uma forma de "livre-arbítrio", seguindo a tradição libertária. Este é um ponto enfatizado tanto por Bobzien quanto por Long:

É virtualmente certo que o conceito de livre-arbítrio em Epicteto, longe de requerer a liberdade da vontade em relação ao destino (ou seja, um futuro inteiramente aberto, um conjunto de possibilidades alternativas ou escolhas), pressupõe, na verdade, a disposição pessoal em aquiescer com o que foi pré-determinado. Aquilo que o interessa não é nem a liberdade da vontade em relação à causação anterior nem a atribuição às pessoas de um futuro aberto e poder indeterminado de escolha. Trata-se, na verdade, da liberdade em ser constrangido por (enquanto distinto de acompanhar) contingências externas (...) (LONG, 2002, p. 221, tradução nossa).

Não há nenhuma evidência de que este conceito tenha alguma coisa a ver com escolhas entre alternativas, sem mencionar decisões livres e isoladas (causalmente

\footnotetext{
${ }^{1} \mathrm{~A}$ nosso ver, seria possível associar estes dois sentidos de liberdade àquilo que Isaiah Berlin chamou de liberdade "negativa" e "positiva" - a negativa como simples ausência de constrangimento externo, e a positiva como exercício pleno de nossa autonomia. Mas não temos espaço para desenvolver esta ideia aqui.
} 
indeterminadas), ou causalidade do agente. (...). Assim como em Crisipo, não há nenhum indício de que Epiteto considerasse que a mesma pessoa, com as mesmas crenças e desejos, nas mesmas circunstâncias, pudesse agir de forma diferente, no sentido de suas ações serem causalmente indeterminadas. A interpretação segundo a qual, para Epiteto, somos causalmente indeterminados quando damos um assentimento e quando queremos algo (no sentido de que nossa escolha não é prédeterminada dentro do limite estrito daquilo que depende de nós) é simplesmente equivocada (BOBZIEN, 1998, p. 335, tradução nossa).

Epicteto não mostra nenhum sinal de consciência crítica sobre o problema do compatibilismo. O conceito de Epiteto daquilo que depende de nós - assim como o de Crisipo - não está preocupado com liberdade indeterminista de decisão, ou com a liberdade de agir de outra maneira (BOBZIEN, 1998, p. 338, tradução nossa).

A tese de que a prohairesis é "naturalmente livre", assim, não deve ser confundida com o conceito incompatibilista de livre-arbítrio. Epicteto, seguindo a tradição estoica, é - se usarmos a terminologia do debate contemporâneo compatibilista. A liberdade não consiste em uma ausência de causalidade, mas sim em ser causado internamente e não externamente - como veremos mais adiante, essa é a ideia por trás da famosa metáfora do cilindro de Crisipo.

Finalmente, outra diferença importante para a concepção moderna de liberdade é que para Epicteto - e para os antigos de forma geral - esta se insere dentro de uma investigação sobre a boa vida. Podemos considerar que um dos traços distintivos do tratamento deste tema na modernidade é o de que parte-se da liberdade, anteriormente a qualquer discussão sobre a boa vida. A ideia de que os indivíduos "nascem livres", antes de pertencerem a qualquer sociedade, é uma ideia moderna, que teria parecido estranha aos antigos (TAYLOR, 1985, p. 318). Em função desta "primazia da liberdade", a cultura liberal moderna tende a trabalhar este conceito de uma maneira mais formal e procedimental, uma instância neutra que paira sobre diferentes concepções substantivas de bem - trata-se de uma liberdade, por assim dizer, para escolher entre várias visões da boa vida. O que é enfatizado não é tanto as boas escolhas que fazemos, mas sim nossa capacidade em escolher. À primeira vista, a prohairesis de Epicteto parece ter muitas afinidades com esta visão moderna - vimos, de fato, que há um sentido em que é possível afirmar que todos "nascemos livres" para Epicteto. Mas isto não é correto. A ética dos antigos, como sabemos, consistia, sobretudo, em uma discussão sobre a boa vida ou eudaimonia. Qual é a melhor vida para os seres humanos? A resposta a esta pergunta é que apontará para o valor da liberdade - esta aparece, assim, como componente central de uma determinada concepção substantiva de boa vida. Desta forma, a conexão entre a liberdade e a eudaimonia está, para Epicteto - 
assim como para os estoicos de forma geral - em sua relevância para a ataraxia, ou seja, a tranquilidade da mente, caracterizada pela ausência de perturbações. A ataraxia pode ser compreendida como uma estratégia para lidar com o problema da Fortuna, central nas éticas dos antigos. Distinguir corretamente aquilo que depende de nós e o que não depende, de fato, é fundamental para termos uma boa vida. Como diz Bobzien,

\begin{abstract}
A motivação para tais questões - tal como são em geral apresentadas por Epicteto - é a de determinar como podemos evitar falhas e desapontamentos, e como podemos atingir um estado emocional imperturbado e bem equilibrado. A motivação, assim, é acima de tudo prudencial e pragmática: se tivermos consciência dos limites de nosso poder, nossos planos futuros serão mais realistas (eles provavelmente incluirão mais "se"s e "quando"s) e, consequentemente, nossas decepções futuras serão minimizadas. O campo, portanto, é o da filosofia prática, e da ética, na medida em que esta contribui para atingirmos a felicidade (eudaimonia) (BOBZIEN, 1998, p. 333, tradução nossa).
\end{abstract}

Após esta introdução sobre o significado e relevância da prohairesis, podemos passar para a investigação sobre os possíveis motivos que levaram o estoico Epicteto a adotar um termo aristotélico para designar o conceito mais importante de sua filosofia.

\title{
As possíveis origens do termo prohairesis
}

Como diz Robert Dobbin, todos concordam que foi Aristóteles quem estabeleceu o uso filosófico da prohairesis. Esta palavra, obviamente, já existia na língua grega de sua época, porém o sentido popular original era mais objetivo, referindo-se, sobretudo, ao objeto da escolha (DOBBIN, 1991, p. 112). Em Aristóteles a prohairesis se torna um ato mental, a decisão resultante da deliberação, bouleusis. $\mathrm{O}$ estagirita, assim, lhe confere um sentido mais subjetivo e intencional - o que reflete, podemos considerar, a passagem da uma cultura homérica da honra, mais preocupada com os aspetos externos, visíveis, das ações, para uma cultura democrática onde a dimensão interna do caráter adquire maior relevância, tanto para a percepção do valor dos atos individuais quanto em termos de sua imputabilidade.

Em Aristóteles a prohairesis possui uma dimensão tanto intelectual quanto desiderativa. Este sentido variou historicamente - não vemos em Epicteto a conexão deste conceito com a deliberação e a ação, por exemplo. No entanto, com diz Dobbin, há uma dimensão da prohairesis aristotélica que reencontramos sim em Epicteto: este último afirma que o homem pode ser visto como uma "arquékinéseos", um composto de 
razão e emoção cuja estrutura correta é estabelecida pela prohairesis (DOBBIN, 1991, p. 114), o que, por sua vez, está relacionado aos critérios de voluntariedade (um dos quais é a origem da ação estar no agente, èkphroaireseos - EN III -1111b6-10). Aqui podemos ver um prenúncio da concepção de Epicteto, que associa fortemente a prohairesis à identidade pessoal- "o homem é sua prohairesis" (Disc. III-1.25-26; Cf. DOBBIN, 1991, p. 115)

Conforme já comentamos, o termo prohairesis praticamente desaparece nos primeiros textos estoicos - existe apenas como um conceito secundário a que se faz referência esporadicamente, um tipo de impulso, ormépraktiké, que pode ser entendido como uma "escolha antes da escolha" (INWOOD, 1985, p. 241). Os comentadores divergem sobre como interpretar este fato. Inwood sugere que a expressão foi deliberadamente menosprezada, como uma forma de os estoicos marcarem seu afastamento em relação à filosofia de Aristóteles (INWOOD, 1985, p. 242). Sandbach, por outro lado, aponta para a possibilidade de estes autores simplesmente não terem tido acesso aos textos do estagirita (SANDBACH, 1985, p. 53). De fato, como se sabe, as obras esotéricas de Aristóteles teriam desaparecido por muitos anos antes de ressurgirem no século I A.C.

Independentemente das razões, o fato de a prohairesis ter tido pouca relevância na tradição estoica torna mais difícil entender a centralidade do termo em Epicteto. A seguir passaremos à exposição de algumas posições sobre este problema.

A) A posição de Long.

A. A. Long considera que o termo remete, sim, a Aristóteles. Como vimos, o estagirita o usa para designar a decisão, que possui uma dimensão tanto intelectual quanto desiderativa, que finaliza a deliberação e leva à ação. A principal afinidade com o conceito de Epicteto estaria na ênfase de Aristóteles no fato de que a prohairesis, enquanto desejo deliberado, se aplica somente "àquilo que depende de nós" (EN III 1113a10). Além disso, a concepção aristotélica também anteciparia a associação feita por Epicteto entre este conceito e a identidade pessoal, na medida em que para Aristóteles a prohairesis é o melhor critério para avaliarmos o caráter de uma pessoa (EN III -1112a2). Finalmente, a própria integração entre intelecto e desejo também possui afinidades com a concepção de Epicteto (LONG, 2002, p. 213). Long se apressa em dizer que existem diferenças importantes entre as duas noções, devido a elementos da psicologia estoica mantidos por Epicteto, particularmente a tese de que a alma possui 
apenas uma parte racional. Comportamentos irracionais, assim, são associados a um mal funcionamento da própria razão, e não, como em Aristóteles, à intervenção de uma faculdade não-racional. Como resultado disso, para Epicteto a prohairesis está atuante o tempo todo em nosso cotidiano, enquanto para Aristóteles isto ocorre apenas quando o agente procura organizar suas atividades práticas segundo princípios racionais (LONG, 2002, p. 213). Apesar destas diferenças, Long considera que o principal objetivo de Epicteto ao cunhar este conceito foi o de especificar as funções autônomas da mente, distinguindo-as das funções passivas de receptores de impressões. Como vimos, ambas são abarcadas pelo conceito estoico tradicional de hêgemonikon. Como já comentamos, Epicteto teria cunhado um novo termo para designar apenas a faculdade que faz uso das impressões, e, segundo a interpretação de Long, o termo prohairesis teria sido adotado devido à forte conexão estabelecida por Aristóteles com "aquilo que depende de nós" (LONG, 2002, p. 214).

B) A posição de Dobbin.

Dobbin acredita que Epicteto de serve do termo prohairesis para responder a críticas dos peripatéticos aos estoicos, sobretudo no contexto do debate sobre o determinismo.

Sabe-se, de fato, que os estoicos são deterministas: não existe contingência a nível ontológico, tudo é estabelecido de acordo com o logos divino de Zeus, imanente à natureza, segundo uma concepção providencial de bem (não temos tempo, aqui, de analisar mais de perto algumas peculiaridades do determinismo estoico, como, por exemplo, o fato de não se tratar propriamente de uma relação de causa-e-efeito). A forma de trabalhar esta questão, assim como sua importância, irá variar, obviamente, de autor para autor. Segundo Dobbin, Zenão e Cleantes tratavam a relação entre moralidade e determinismo como algo relativamente não problemático. Foi Crisipo quem, em função de críticas de Carnéades, estruturou melhor o problema. No De Fato vemos Cícero expor a famosa metáfora do cilindro de Crisipo, com a distinção entre causas próximas/auxiliares e principais/perfeitas: no caso do cilindro, o empurrão que o faz descer a ladeira é a causa próxima, mas a principal é a forma do cilindro (CÍCERO, De Fato 42-43). A ideia, aqui, seria a de mostrar que na ação humana o estímulo externo, através das phantasia, é apenas uma causa secundária, ainda que próxima. A causa principal das ações do agente é seu assentimento, que, por sua vez, é um reflexo de seu caráter. 
A partir do século I DC, estrutura-se um debate entre peripatéticos e estoicos acerca da questão do determinismo. Este debate muitas vezes gira, justamente, em torno do termo prohairesis. Aristóteles, de fato, defendia uma ontologia não determinista, afirmando que a escolha (prohairesis) se dá sempre em função “daquilo que é contingente e depende de nós" (EN III-3 -1112b6-10). No século III D.C, Alexandre de Afrodísia incorporará esta posição no debate com os estoicos, afirmando que não há espaço, no determinismo destes últimos, para a prohairesis, ou seja, para a escolha livre. A filosofia estoica, assim, inviabilizaria a liberdade, portanto a responsabilidade moral, e, em última instância, a própria moralidade (DE FATO, 180.3-10, apud DOBBIN, 1991, p. 123).

Dobbin acredita que foi este tipo de posição que levou Epicteto a adotar o termo prohairesis. No decorrer do debate com os peripatéticos, era comum que estes últimos incorporassem termos estoicos em suas críticas, como uma forma, por assim dizer, de vencer os estoicos em seu próprio terreno (DOBBIN, 1991, p. 123). Epicteto, assim, estaria adotando o mesmo procedimento: usar um termo de origem aristotélica para responder às críticas dos peripatéticos - um pouco como se dissesse "ah, o problema é a prohairesis? Não seja por isso".

A prohairesis de Epicteto, de fato, entendida como o núcleo duro de nossa identidade pessoal, corresponde àquilo que Crisipo chamava de causa interna ou perfeita - ligando-se assim diretamente à estrutura montada por este último para resolver o problema da compatibilidade entre determinismo e responsabilidade moral. A principal crítica dos peripatéticos à solução crisipiana é a de que não somos responsáveis por nosso caráter - de onde resultaria, segundo Dobbin, a insistência de Epicteto na autonomia absoluta da prohairesis, ao afirmar que nenhum fator externo tem o poder de atuar diretamente sobre ela, nem mesmo Zeus (Disc. I-1.24).

A tese de Dobbin é sem dúvida instigante. Podemos, porém, apontar para duas fraquezas: primeiro, o fato de Alexandre de Afrodísia, que Dobbin aponta como a principal referência no uso do termo prohairesis no debate entre estoicos e peripatéticos, só ter escrito mais de um século após a morte de Epicteto. Dobbin, obviamente, tem consciência disto, e comenta, neste sentido, que é razoável supor que os principais elementos deste debate já existiam antes do tempo de Alexandre (DOBBIN, 1991, p. 126). A outra fraqueza é que o debate sobre determinismo não parece ocupar um lugar suficientemente central nos textos de Epicteto para que este fosse o principal motivo para a escolha de um termo tão importante em sua filosofia. A 
noção de liberdade (èleutería), obviamente, ocupa sim um lugar de destaque - esta, porém, é compreendia mais a partir do contraste entre aquilo que o agente controla e não controla do que com o problema do determinismo. Discussões de caráter ontológico, de fato, não parecem interessar muito a Epicteto, que prefere focar a dimensão ética da liberdade, em sua contribuição para a boa vida.

C) A posição de Sandbach e Dihle.

Outra tese sobre o uso do termo prohairesis em Epicteto é a de que sua origem estaria não na tradição filosófica, mas sim no uso comum que existia na língua grega da época. Esta é a posição de Sandbach (1985, p. 72 (n57)).

Conforme já comentamos, a prohairesis não era um termo técnico inventado por filósofos como Aristóteles, mas sim uma palavra que fazia parte da linguagem cotidiana dos gregos (lembremos que o grego ainda era uma língua muito usada no mundo romano nos tempos de Epicteto - a ponto, por exemplo, do Imperador Marco Aurélio ter escrito suas Meditações em grego, e não em latim; e foi em grego que Ariano transcreveu as aulas de Epicteto nos Discursos, indicando, assim, que este dava seus cursos usando esta língua). Sandbach comenta que no tempo de Epicteto esse termo tinha um significado genérico de "propósito" ou "diretriz", e, por extensão, de "caráter moral" - portanto uma acepção que possui, sim, certa afinidade com o sentido técnico que adquire em Epicteto. Segundo Sandbach, este significado cotidiano pode ser encontrado em autores como Demóstenes, Polibus e Dionísio de Alecarnasso (SANDBACH, 1985 p. 72 (n57); DOBBIN, 1991, p. 124). Albrecht Dihle concordaria com a linha adotada por Sandbach (DIHLE, 1982, p. 60 (n49)).

A favor desta posição está o fato de que Epicteto com frequência se expressa através de um vocabulário popular. Este ponto está ligado a dois aspectos: primeiro, a origem humilde de Epicteto, um ex-escravo; segundo, os textos que chegaram até nós são transcrições de cursos de Epicteto, e tendemos a nos expressar de forma mais coloquial quando damos aulas do que quando escrevemos um texto. Obviamente, um termo tão central nem sua doutrina com certeza passou por uma elaboração conceitual mais cuidadosa. No entanto, não é improvável que a escolha do termo tenha sido influenciada pela linguagem mais coloquial que Epicteto usava em suas aulas.

D) A posição de Kahn. 
Finalmente, temos um quarto tipo de posição em Charles H. Kahn, que enfatiza o caráter inovador do conceito de prohairesis em Epicteto. Kahn considera que esta dimensão teria levado Epicteto a usar um termo filosófico fora de moda, estranho à tradição estoica, para marcar, justamente, que estava elaborando uma ideia nova (KAHN, 1988, pp. 252-3).

Qual seria exatamente este caráter inovador? Kahn afirma que Epicteto usa a prohairesis para introduzir uma concepção individualizada e pessoal de "self", algo que não existia antes, tanto no uso filosófico quanto corriqueiro da palavra. Este maior grau de individualização seria obtido a partir da síntese de diversas ideias: a prohairesis em Epicteto, de fato, pode significar razão, poder arquitetônico, self, virtude e caráter moral. Em suma, pode significar intelecto, mente, alma, liberdade, caráter, virtude (DOBBIN, 1991, p. 134).

A tese de Kahn implica que Dobbin esteja errado sobre o uso da prohairesis no debate entre peripatéticos e estoicos antes da época de Alexandre de Afrodísia. Se Epicteto quis usar um termo antigo, "fora de moda", isso quer dizer que este não estava em voga nas discussões filosóficas de seu tempo.

A favor desta posição estaria o fato, que já comentamos, de que havia no antigo sentido da prohairesis em Aristóteles o germe da concepção de Epicteto: a ideia do ser humano como uma "arquékinéseos", cuja estrutura é estabelecida pela prohairesis. Esta afinidade poderia explicar porque Epicteto optou por usar esta antiga noção para expressar o novo conceito que estava elaborando, no qual a noção de identidade pessoal, de "verdadeiro eu", exerce um papel central.

\section{Conclusão.}

Vimos que o uso do termo prohairesis por Epicteto pede algum tipo de explicação, e exploramos algumas hipóteses levantadas por comentadores sobre este ponto: a- Epicteto teria adotado um termo aristotélico propositadamente, devido a afinidades conceituais entre sua concepção e a de Aristóteles; b- a origem do termo estaria no debate entre peripatéticos e estoicos sobre determinismo e responsabilidade moral; c- sua origem estaria no uso popular da palavra no mundo grego e romano; dEpicteto teria usado uma palavra antiga, pouco usada em sua época, para marcar o caráter inovador do conceito que estava criando, inspirando-se parcialmente na afinidade deste conceito com alguns aspectos em Aristóteles. Existe, obviamente, uma complementariedade entre as hipóteses (a) e (d), o que nos permitiria agrupar três 
posições principais, a da afinidade conceitual com Aristóteles, a da linguagem coloquial, e a do debate com os estoicos sobre determinismo.

Infelizmente nunca saberemos ao certo se alguma destas hipóteses é a correta. É relevante, no entanto, investigar quais são as explicações mais prováveis. Este tipo de análise lança uma nova luz sobre o significado deste conceito rico e tão importante para a filosofia de Epicteto.

\section{REFERÊNCIAS BIBLIOGRÁFICAS}

ARISTÓTELES. Ética a Nicômaco. (trad Antônio de castro Caeiro). São Paulo: Editora Atlas, 2009.

BOBZIEN, S. Determinism and Freedom in Stoic Philosophy. Oxford: Clarendon Press, 1998.

CÍCERO. Sobre o Destino. (trad de José Rodrigues Seabra Filho). São Paulo:

Ed Nova Alexandria, 1993.

DIHLE, A. The Theory of Will in Classical Antiquity. Berkeley:

UniversityofCalifornia Press, 1982

DOBBIN, R. "Phroiaresis in Epictetus”. In Ancient Philosophy, 11 (1991).

EPICTETO: The Discourses and Manual, Together With Fragments of His

Writings. Ed. By P. E Matheson. Oxford: The Clarendon Press, 2009.

INWOOD, B.: Ethics and Human Action in Early Stoicism. Evinity

Publishing, 1985.

KAHN, H. C.: "Discovering the Will: from Aristotle to Augustine". In

DILLON, J. M \& LONG, A. A. The Question of "Eclecticism" - studies in later greek philosophy (cap. 9). Berkeley: University of California Press, 1988.

LONG, A. A. Epictetus - a stoic and socratic guide to life. Oxford: Clarendon

Press, 2002

SANDBACH, F. H. Aristotle and the Stoics. Cambridge: Cambridge

University Press, 1985.

TAYLOR, C. Philosophical Papers vol 2 - philosophy and the human sciences. Cambridge: Cambridge University Press, 1985. 